DOI: $10.5216 /$ racs.v4.59238

Considerações sobre processos colaborativos de co-teorização: diálogos entre o projeto Milpas Educativas e o Núcleo Takinahakỹ de Formação Superior Indígena

Alexandre Herbetta ${ }^{1}$

RESUMO

Este texto busca colocar em diálogo o projeto Milpas Educativas (ME) e o projeto do Núcleo Takinahakỹ de Formação Superior Indígena (NTFSI). Desta forma, reflete de forma inicial sobre caminhos possíveis a serem desenvolvidos com o avanço de ambos os projetos na construção coletiva de um horizonte político-educacional-pedagógico para o Bem Viver. Ademais, apresenta mais detalhadamente a dinâmica dos Temas Contextuais (TCs), centro da experiência do Curso de Licenciatura Intercultural Indígena, componente do NTFSI.

PALAVRAS-CHAVE: Bem-viver. Política educacional. Metodologia.

Consideraciones sobre los procesos colaborativos de co-teorización: diálogos entre el proyecto de Milpas Educativas y el Núcleo de Takinahakỹ de la Formación Indígena Superior

\title{
RESUMEN
}

Este texto busca poner en diálogo el proyecto Milpas Educativas (ME) y el proyecto del Núcleo Takinahakỹ de Formación Superior Indígena (NTFSI). De esta forma refleja de forma inicial sobre caminos posibles a ser desarrollados con el avance de ambos proyectos en la construcción colectiva de un horizonte político-educativo-pedagógico para el Bien Vivir. Además, presenta más detalladamente la dinámica de los Temas Contextuales (TCs), centro de la experiencia del Curso de Licenciatura Intercultural Indígena.

PALABRAS ClAVE: Bien Vivir. Política educativa. Metodología.

\footnotetext{
${ }^{1}$ Professor do Núcleo Takinahakỹ de Formação Superior Indígena e do Programa de Pós-Graduação em Antropologia Social da Universidade Federal de Goiás (UFG). Goiânia, GO, Brasil. E-mail: alexandre herbetta@yahoo.com.br.
}

Dossiê Práticas de bem viver: diálogos possíveis entre o Núcleo Takinahakỹ e Milpas Educativas 


\title{
Introdução
}

O objetivo deste texto é o de colocar brevemente em diálogo, princípios e experiências relacionados ao projeto Milpas Educativas (ME) e ao projeto do Núcleo Takinahakỹ de Formação Superior Indígena (NTFSI). Desta forma, busco refletir de forma inicial sobre caminhos possíveis a serem desenvolvidos com o avanço de ambos os projetos na construção coletiva de um horizonte político-educacional-pedagógico para o Bem Viver. Segundo o texto do projeto ME, o bem viver

\begin{abstract}
é um conceito polissêmico que sintetiza uma filosofia de vida comum a diferentes povos indígenas caracterizado pela integração sociedade-natureza. Cada povo indígena, de acordo com sua cosmovisão, tem uma concepção própria de Bem-Viver que engloba as dimensões sociais interconectadas: espiritual, axiológica, produtiva, alimentar, educacional, etc (Projeto ME, 2016, p.2).
\end{abstract}

O projeto $\mathrm{ME}$ conta com a participação de populações indígenas de 5 estados mexicanos: Chiapas (Tseltales, Tsotsiles y Ch’oles), Yucatán, Puebla, Oaxaca, Michoacán e busca

mejorar la pertinencia y relevancia de los procesos educativos formales e informales de niñas y niños indígenas, consolidando un modelo educativo intercultural multilingüe que contribuya al buen vivir de sus familias y comunidades, generando una alternativa educativa que responda a los retos del sistema educativo en contextos indígenas (Projeto ME, 2016, p.1)

É importante introduzir, brevemente, portanto, o meu lugar de fala, ou seja, a partir de onde posso fazer comparações e inferências sobre os projetos em tela.

Sou docente do Núcleo Takinahakỹ de Formação Superior Indígena (NTFSI), na Universidade Federal de Goiás (UFG), o qual constitui espaço de referência, no Brasil, em pesquisa e formação no campo da educação escolar indígena e da educação intercultural. Constitui, também, a possibilidade de acesso e permanência de indígenas no ensino superior brasileiro. Atuo de maneira mais próxima às populações Krahô e Apinajé, base dos casos mencionados neste texto.

O NTFSI existe há doze anos e surgiu como parte de uma política pública de formação superior indígena que se intensificou na década de 2000 , especialmente com a formação da Secretaria de Educação Continuada, Alfabetização, Diversidade e Inclusão (SECADI) e as ações do Programa de Apoio à Formação Superior e Licenciaturas Interculturais Indígenas (PROLIND).

Dossiê Práticas de bem viver: diálogos possíveis entre o Núcleo Takinahakỹ e Milpas Educativas 
Tais políticas são demandadas, entretanto, pelo movimento indígena desde a década de 1980. Estas políticas, assim como outras, busca ressaltar práticas de autonomia em detrimento a política indigenista anterior baseada na noção de tutela e integração. Para Bertely,

(...) a autonomia escolar pode ser expressa de formas tão diferentes quanto: conflito e resistência política à cultura dominante, a justaposição estratégica do discurso oficial e do étnico, adaptação aos padrões de socialização nativa, abertura ao conhecimento que representa a sociedade dominante; em todos os casos os povos indígenas e tribais atualizam, inventam, recriam e reconfiguram a cultura escolar através de uma autonomia de fato e que é relacional, cuja variabilidade depende da sua história social, o que é étnica e politicamente significativo para os atores (2000, p. 49).

A autonomia em referência pode ser observada em uma série de transformações que estão sendo estabelecidas - em diversos graus - nas várias escolas indígenas e suas comunidades participantes do projeto NTFSI. Vale ressaltar que cada escola de cada população indígena avança de maneira distinta e se encontra em momentos diferentes no desenvolvimento do projeto.

\begin{abstract}
Eixos de sustentação do curso de Licenciatura Indígena aqui proposto são a Diversidade e a Sustentabilidade, definidos com base na realidade das sociedades indígenas, no reconhecimento da diferença étnica, na situação em que cada comunidade vive e no seu relacionamento com outros povos. Levaram-se em conta tanto os contextos culturais, linguísticos, políticos e econômicos quanto os relacionamentos cotidianos dessas sociedades com a não-indígena; não se esqueceu de dar atenção também aos projetos político-pedagógicos das escolas indígenas, às políticas linguísticas adotadas nas aldeias e aos programas alternativos de desenvolvimento econômico em andamento nas comunidades e, ainda, aos projetos de futuro desses povos (Projeto Político Pedagógico NTFSI, 2006).
\end{abstract}

Trabalhamos com escolas oficiais, ou seja, ligadas ao sistema oficial do estado brasileiro, mais especificamente, às Secretarias de Educação de cada estado (SEDUCs) e ao Ministério da Educação (MEC), de maneira geral. Buscamos a formação de professorxs e lideranças que promovam junto a suas comunidades, de maneira horizontal e simétrica, "desde abajo" como escutei várias vezes nos eventos em que participei no projeto Milpas Educativas (ME), processos de transformação das escolas indígenas.

Tais transformações se dão concretamente por meio da criação e efetivação de novas práticas pedagógicas, de uma reforma curricular profunda e pela consolidação de um novo projeto político pedagógico (PPP). Segundo Grupioni, 
como um movimento pendular pode ser dito que a escola percorreu um longo caminho do passado para o presente, de algo que foi imposto aos índios a uma demanda que está sendo reivindicado por eles. Utilizada no passado para culturalmente aniquilar essas pessoas, hoje é vista como um instrumento que pode trazer de volta a sensação de etnia, resgatando valores, práticas e histórias borradas pelo tempo e pela imposição de outros padrões culturais (2006, p.44).

O NTFSI é constituído por curso de graduação e de pós-graduação no nível de especialização. Atualmente, conta com cerca de 300 professorxs indígenas dos estados de Goiás, Mato Grosso, Minas Gerais, Tocantins e Maranhão, pertencentes a 27 distintas populações, entre elas, os Krahô, Apinajé, Javaé, Karajá, Guarani, Xambioá, Canela, Gavião, Guajajara, Juruna, Krikati, Tapirapé, Xerente, Mehinako, Kamayurá, Kayapó, Kuikuro, Timbira, Waurá, Xavante, Xacriabá e Tapuia. Há cerca de 150 professores indígenas formados em nível de graduação e 100 em nível de especialização.

Neste contexto, o NTFSI buscou se formar e tenta se desenvolver sempre em relação às epistemologias indígenas. $\mathrm{O}$ curso tem sua dinâmica voltada para o diálogo intercultural crítico (WALSH, 2013), o qual referencia o Projeto Político Pedagógico (PPP) do mesmo, a matriz curricular e as práticas pedagógicas produzidas. A noção de interculturalidade é entendida igualmente enquanto conflito (GASCHÉ, 2008). Cada professor indígena cursa uma matriz curricular básica de dois anos e uma matriz específica de mais três, quando opta por se aprofundar, de modo transdisciplinar, nas áreas da linguagem, natureza e cultura.

O NTFSI trata, portanto, de refletir, sobre a possibilidade de que a escola seja e/ou produza (novos) espaços de protagonismo, autonomia e bem estar, o que se dá por meio da elaboração de atitudes decoloniais baseadas nos modos próprios de aprendizagem de cada população, que emergem nas práticas pedagógicas comunitárias. Trabalha-se, assim, com a consolidação de pedagogias contra hegemônicas em direção ao Bem Viver, apontando para outros horizontes epistemológicos, filosóficos e ontológicos.

Para Freire,

a primeira condição para que um ser pudesse exercer um ato comprometido era a sua capacidade de atuar e refletir. E exatamente esta capacidade de atuar, operar, transformar a realidade de acordo com finalidades propostas pelo homem, a qual esta associada sua capacidade de refletir, que o faz um ser da práxis. Se ação e reflexão, como constituintes inseparáveis da práxis, são a maneira de existir, isto não significa, contudo, que não estão condicionadas, como se fossem absolutas, pela realidade em que está o homem $(1982$, p. 8). 


\title{
1 Dinâmica dos Temas Contextuais (TCs)
}

Tais pedagogias contra hegemônicas se concretizam por meio da dinâmica dos temas contextuais (TC). A expressão tema contextual, assim como sua dinâmica, tem origem na história de vida da professora do NTFSI e ex-coordenadora do Núcleo, Maria do Socorro Pimentel da Silva, que se aprofunda na questão ainda neste dossiê.

Nessa direção, segundo Pimentel, podemos entender o tema contextual

\begin{abstract}
como uma ação pedagógica que rompe com o tecnicismo praticado no ambiente escolar, o qual rejeita os laços e as intercomunicações com seu meio e o insere num compartimento, que é aquele da disciplina cujas fronteiras destroem arbitrariamente as condições do diálogo entre ciências e os mais distintos conhecimentos (PIMENTEL DA SILVA, 2013).
\end{abstract}

Pode-se dizer ainda que, de início, o tema contextual surge para se diferenciar da noção de disciplina. Esta, como se viu, não se adequa à prática pedagógica da escola indígena, pois recorta os saberes, percebendo-os como universais e vindos de fora. Com o tema contextual, afinal, a cultura cotidiana (local) é o ponto de partida para o entendimento de novos saberes. Assim, para os Xerente, a "ciência indígena... (os saberes) dialogam entre si, não estão fragmentadas em caixinhas. O saber é coletivo... passa através das gerações... conectando" (III Seminário do Curso de Especialização em Educação Intercultural e Transdisciplinar: gestão pedagógica).

Há outras várias maneiras de se definir o tema contextual. Para Manaijè Karajá, o tema contextual é como o espalhamento do conhecimento. Para Silvia Xerente, é a possibilidade de convivência intercultural, em suas palavras, de se viver em relação com os dois mundos, a aldeia e a cidade. Para Dodanin Piiken, é a possibilidade de se trabalhar com a tradição, mas de uma forma contemporânea (III Seminário do Curso de Especialização em Educação Intercultural e Transdisciplinar: gestão pedagógica).

O tema é, portanto, mais do que uma simples oposição à disciplina. Ele põe em movimento questões centrais da relação entre indígenas e a contemporaneidade. Favorece o diálogo entre o universo da aldeia e o da cidade. E estabelece uma dinâmica que favorece a reflexão e a prática sobre o mundo, mas do ponto de vista indígena, desvelando uma outra pedagogia - não disciplinar.

Os TCs são experienciados e realizados concretamente ao longo dos estágios docências supervisionados, componente obrigatório e parte do PPP, no Curso de Licenciatura 
Intercultural Indígena. Cada discente deve cursar seis semestres (Estágio 1, 2, 3, 4, 5 e 6) nos quais criará e experimentará a dinâmica proposta nos TCs, em direção a uma reformulação radical das matrizes curriculares das escolas e da construção de um novo PPP.

Num curso de licenciatura com este caráter, o estágio docência supervisionado é o "coração" do curso. Sheila Baxy Apinajé, Tais Pocuhto Krahô e Daniel Bidjawari Karajá apresentarão experiências concretas, neste sentido, no dossiê.

O território é a base das práticas pedagógicas propostas por meio dos TCs, isto aponta, pois, para um aspecto fundamental das epistemologias indígenas. É a partir dele que se produz conhecimento e é por meio dele que se conhece o mundo. Tratam-se de territórios epistêmicos.

É o que afirma Daniel Munduruku, no Brasil, a partir da noção de letramento de mundo. Segundo o mesmo,

\begin{abstract}
uma das lembranças mais agradáveis que tenho da minha infância é a de meu avô me ensinando a ler. Mas não ler as palavras dos livros e, sim, os sinais da natureza, sinais que estão presentes na floresta e que são necessários saber para poder nela sobreviver. Meu avô deitava-se sobre a relva e começava a nos ensinar o alfabeto da natureza: apontava para o alto e nos dizia o que o voo dos pássaros queria nos informar. Outras vezes fazia questão de nos ensinar o que o caminho das formigas nos dizia. E ele nos ensinava com muita paciência, com a certeza que estava sendo útil para nossa vida adulta. Aos poucos fui percebendo que aquilo era uma forma natural de aprendizado e que tudo era real. Mesmo quando nos falava dos mistérios da natureza, das coisas que minha cabeça juvenil não compreendia, sentia que o velho homem sabia exatamente o que estava nos ensinando. Fazia isso nos contando histórias das origens, das estrelas, do fogo, dos rios. Ele sempre nos lembrava que, para ser conhecedor dos mistérios do mundo, era preciso ouvir a voz carinhosa da mãe-terra, o suave murmúrio dos rios, a sabedoria antiga do irmão-fogo e a voz fofoqueira do vento, que trazia notícias de lugares distantes (2017, p.1).
\end{abstract}

A problematização é central para a dinâmica do TC, que deve ser pensado de preferência em reuniões coletivas ou assembleias nas quais demandas comunitárias sejam então identificadas e debatidas. Nesse sentido, a relação estabelecida entre escola e comunidade é fundamental. A escola deve ser coletivizada. Para Creuza Prumqwyj Krahô, a escola deve ser o pátio, que na epistemologia mehi (indígena) é o local de debate coletivo e comunitário, onde decisões fundamentais para a vida indígena são tomadas.

Deve-se igualmente romper com a noção de tempo típica de uma matriz curricular disciplinar, como hipoteticamente abaixo. Não é possível a prática de um saber transdisciplinar, formato em um modelo que fragmenta o conhecimento em tempos marcados e reduzidos. As matrizes curriculares da escola indígena ainda são em grande maioria no regime disciplinar. Para Lewis Gordon (2011), o regime disciplinar aponta para um modo de 
produção e organização do conhecimento vinculado aos saberes ocidentais e à noção de modernidade, reforçando categorias como hierarquia e descontextualizando a realidade.

Para o autor, a disciplina reduz os saberes ao ocidental e fortalece a noção de poder, baseada no que chama de fetichização do método, quando este é mais importante do que o conteúdo.

\begin{tabular}{|l|l|l|l|l|}
\hline \multicolumn{1}{|c|}{ Segunda-feira } & \multicolumn{1}{|c|}{ Terça-Feira } & \multicolumn{1}{|c|}{ Quarta-Feira } & \multicolumn{1}{c|}{ Quinta-Feira } & \multicolumn{1}{c|}{ Sexta-Feira } \\
\hline Matemática & Português & Ciências & História & Artes \\
\hline Língua Indígena & Geografia & Cosmologia Indígena & Português & Português \\
\hline Ciências & Educação Física & Matemática & Saberes Indígenas & Língua Indígena \\
\hline \multicolumn{1}{|c|}{$[\ldots]$} & {$[\ldots]$} & {$[\ldots]$} & {$[\ldots]$} & {$[\ldots]$} \\
\hline
\end{tabular}

Nesta direção, o intelectual Piiken Krahô certa vez me comentou sobre a impossibilidade de se inserir os conhecimentos implícitos à Yat jõn Pin (Festa da Batata) em uma matriz disciplinar (como acima), que fragmenta e descontextualiza o conhecimento (PIIKEN, 2013). Segundo ele, como falar de um evento tão fundamental para o universo mehi, se a história da festa é recortada e ministrada na referida disciplina? A música é descontextualizada e é transmitida na disciplina de artes e assim sucessivamente (Ibidem). Segundo Piiken, a matriz disciplinar acaba com a Yat jõn Pin, sobram apenas disciplinas.

$\mathrm{Na}$ mesma direção, conforme outrxs docentes indígenas, o uso do tempo é fundamental para a efetivação dos temas contextuais. No tema contextual, a problematização coletiva é esticada ao longo da semana por meio de atividades contextualizadoras. Esticar para Júlio Kamer Apinajé aponta para o caráter relacional das ontologias indígenas (2012). Segundo o mesmo, para se tratar de um TC deve-se atentar para as diversas relações possíveis e específicas dele (Ibidem).

Cada TC, portanto, tem como suporte um tempo de fluxo contínuo, como hipoteticamente abaixo. O tema contextual de Julio Kamer Apinajé, por exemplo, parte da questão das queimadas em território indígena, problema sério do território indígena, o qual é explorado, por meio de determinadas atividades pedagógicas, ao longo da semana (2012). Ele indica uma interessante relação entre queimadas e musicalidade. Para o autor, a musicalidade panhi codifica e dialoga com o cerrado, desta forma, o bioma é musicado. Para Kamer, se as crianças aprendem este repertório musical, apreendem o território e podem cuidar dele, mitigando os efeitos devastadores das queimadas. 
Tema Contextual:

\begin{tabular}{|l|l|l|l|l|}
\hline \multicolumn{1}{|c|}{ Segunda-feira } & \multicolumn{1}{|c|}{ Terça-Feira } & \multicolumn{1}{c|}{ Quarta-Feira } & \multicolumn{1}{c|}{ Quinta-Feira } & \multicolumn{1}{c|}{ Sexta-Feira } \\
\hline $\begin{array}{l}\text { Atividades de } \\
\text { Problematização }\end{array}$ & $\begin{array}{l}\text { Atividades de } \\
\text { Explicação/Aconselha } \\
\text { mento }\end{array}$ & $\begin{array}{l}\text { Atividades de } \\
\text { pesquisa }\end{array}$ & Atividades Práticas & $\begin{array}{l}\text { Atividades } \\
\text { Comunitárias }\end{array}$ \\
\hline
\end{tabular}

As práticas pedagógicas decorrentes das atividades planejadas e efetivadas (como acima) ao longo dos TCs buscam trabalhar com a problematização das questões, que podem ser intra e interculturais. O intelectual Emilio Ninho Apinajé, por exemplo, partiu de uma pesquisa sobre os usos tradicionais do babaçu, espécie comumente achada no território indígena e valorizada economicamente, e passou a discutir formas capitalistas atuais de exploração do recurso. Ressalta-se que a pesquisa é fundamental para a produção dos TCs, não há, portanto, uma indissociabilidade entre pesquisa e docência.

Nota-se, igualmente, que a base das atividades são sempre práticas, pois se articulam com uma noção de aprendizagem própria do pensamento indígena. Roberto Caxet Krahô afirma que se aprende em movimento. E, também, atividades comunitárias, as quais fortalecem o vínculo entre escola e comunidade, produzindo efetivamente uma nova escola, comunitária (2013).

O tema contextual busca estabelecer, portanto, um espaço na matriz curricular escolar possível para a prática transdisciplinar, a qual gera, então, uma reorganização dos conteúdos e das relações: entre escola e comunidade, entre gerações, entre saberes indígenas e nãoindígenas. Estes espaços passam a ter como centro as epistemologias indígenas e, consequentemente, fortalecem as línguas nativas.

Desta forma, as diversas epistemologias indígenas emergem nas atividades elaboradas e seus aspectos centrais são claramente percebidos. As atividades pedagógicas que, conforme mencionado, partem do território, avançam por sobre outros temas, apontam para uma ruptura com algo central de uma epistemologia ocidental, qual seja a dicotomia natureza-cultura. Segundo Gersem Luciano Baniwa (2014), no Brasil, a grande marca do ocidente é distinguir estes dois domínios, objetificando o primeiro. Para o autor, esta é a base da possibilidade de exploração predatória do planeta e da consequente degradação da vida.

Conforme Baniwa, ainda, ao objetificar a natureza, legitimando a predação da mesma, a matriz epistemológica ocidental busca apagar a espiritualidade presente nos seres, espécies e 
objetos do mundo. Ora, se cada processo educativo tem a ver com cada cosmovisão e epistemologia, deve-se problematizar os modos de aprender. O sonho, por exemplo, pode ser importante momento de aprendizagem.

Os projetos apresentados expressam, portanto, de maneira bastante inovadora, os domínios da epistemologia indígena, e desenvolvem atividades em que os elementos do mundo e da vida estão ligados e são movidos de maneira não dicotômica.

Os conhecimentos ocidentais não são eliminados, mas ajuntados. Segundo Pereira (2015), que fez seu mestrado acerca de elementos constituintes do NTFSI,

pude perceber como o ajuntar do aluno Xavante é importante para compreensão de uma realidade dinâmica e articulada entre o mundo indígena e não indígena. O que quero ressaltar é que os indígenas com quem convivi sempre procuraram ajuntar ou melhor colocar no mesmo status os conhecimentos dos dois mundos (indígena e não indígena), por isso a importância desta categoria (p. 105-106).

É similar ao que Cusiquanqui afirma em relação à noção Aymara, ch'ixi. Segundo a autora ch'ixi aponta, para

\begin{abstract}
la mezcla abirrada que somos las y los llamados mestizas y mestizos. La palabra ch'ixi tiene diversas connotaciones: es un color producto de la yuxtaposición, em pequenos puntos o manchas, de los colores opuestos o contrastados: el blanco y lo negro, el rojo y el verde etc resultante de la mezcla imperceptible del blanco y el negro, que se confunden para la percepción sin nunca mezclarse del todo. La nocion ch'ixi, como muchas outras (allqa, ayni) obedece a la idea aymara de algo que es y no es, es decir, a la logica del tercero incluído. Un color gris ch'ixi es blanco y no es blanco a la vez, es blanco y tambien es negro, su contrario (p. 69).
\end{abstract}

Entende-se, então, que a dinâmica dos TCs, com foco no território, consegue construir práticas de sustentabilidade, sejam elas de sustentabilidade ambiental, linguística ou cultural. Mais do que isso, consegue tratar da noção de sustentabilidade possível em cada população indígena.

O curso de Educação Intercultural prioriza a autonomia e o fortalecimento das identidades étnicas nesse contexto de confronto e interesses opostos. Prioriza também a sustentabilidade de políticas econômicas, linguísticas, de manutenção cultural e de defesa das terras indígenas (PPC NTFSI, 2006, p. 35).

Neste contexto, as avaliações devem ser entendidas de maneira mais ampla, inclusive, levando em consideração aspectos das respectivas epistemologias. Os Krahô, por exemplo, valorizam a habilidade de falar em público. Desta forma, os temas contextuais promovem atividades pedagógicas que buscam praticar tal habilidade. Ademais, tal habilidade pode ser 
pensada em relação à noção indígena de pahan. Pahan é, mal traduzindo, uma restrição ao contato com o público em geral. Assim, parte das atividades comunitárias dos temas contextuais da escola 19 de Abril, da Aldeia Manoel Alves Pequeno, são realizadas às sextasfeiras, no fechamento da semana. Neste momento, discentes apresentam o resultado das atividades da semana para toda a comunidade, estabelecendo-se um espaço de diálogo e debate comunitário.

Ademais, deve-se ressaltar que cada uma das populações indígenas participantes do projeto do NTFSI constitui institucionalmente um comitê, junto de anciãos, egressos e membros das respectivas comunidades. Cada comitê tem autonomia para criar soluções contextualizadas em suas realidades a partir dos princípios aqui expostos.

A escola 19 de abril, por exemplo, construiu uma matriz curricular que articula a dinâmica dos temas contextuais com a das disciplinas, equilibrando, como dizem, os dois saberes. Tal processo se dá de maneira similar a forma que organizam o mundo, a partir de uma organização social dualista, divido entre os partidos Wacmejè e Katamjè. Importante destacar que as experiências de cada comitê variam bastante, mesmo no interior deles. Buscase seguir o método dos TCs respeitando-se a realidade de cada povo.

Na mesma direção, a escola Panrã da Aldeia Nova/Krahô está construindo seu PPP a partir destes dualismos, estabelecendo um calendário que propõe o tempo seco para os temas contextuais e o tempo chuvoso para a dinâmica disciplinar. Para a intelectual Pocuhto Krahô, a prática do TC faz com que alunxs tenham um desempenho melhor em todos os campos, inclusive nas disciplinas. Para ela, a escola ficou mais alegre.

A proposta do NTFSI não se limita ao nível educacional, se articula aos domínios epistemológicos, ontológicos, linguísticos e políticos. Parte-se do conhecimento local, mas pode-se apreender e problematizar o mundo (sempre do ponto de vista de cada população). Busca-se, portanto, romper com a colonialidade do ser, do poder e do saber por meio da assunção política e real da pluriversidade.

\section{Processos colaborativos de co-teorização: diálogos entre o projeto Milpas Educativas e o Núcleo Takinahakỹ de Formação Superior Indígena}

Como Bertely apresenta neste dossiê, os temas do território, da sintaxis cultural, da interculturalidade crítica, das epistemologias indígenas são centrais na práxis do projeto Milpas Educativas (ME).

Dossiê Práticas de bem viver: diálogos possíveis entre o Núcleo Takinahakỹ e Milpas Educativas 
Refletindo sobre as possíveis relações com o projeto do NTFSI, ambos se apropriam de um repertório conceitual contemporâneo a partir de métodos próprios, apresentando elementos similares e características contrastantes, as quais facilitam a comparação entre os projetos e uma análise crítica deles.

Nesta direção, há uma série de novas práticas e princípios pedagógicos planejados, pensados e efetivados. Um professor de Chiapas, por exemplo, mencionou que com o projeto ME é possível "voltar a reconstruir" práticas culturais deixadas de lado (Taller Interestatal Milpas Educativas, 2018). Outra ME de Chiapas afirmou que seu objetivo principal era o de valorizar a mãe terra (Ibidem).

Neste sentido, para Cusicanqui devemos

Construir nuestra própria ciencia - em un dialogo entre nosotros mismo- dialogar com las ciencias de los países vecinos, afirmar nuestros lazos com las corientes teóricas de Asia y África, y enfrentar los proyectos hegemónicos del norte com la renovada fuerza de nuestras convicciones ancestrales $(2018$, p. 73$)$.

Ambos igualmente se colocam de maneira contrária a escola colonizadora, usada por séculos como estratégia de dominação colonial e desvalorização dos conhecimentos indígenas, constituindo processos evidentes de colonialidade do saber e violência epistêmica (LANDER, 2005: 21-53). Para Lander (2005, p. 27),

\begin{abstract}
as categorias, conceitos e perspectivas eurocêntricas (economia, Estado, sociedade civil, mercado, classes, etc.) se convertem, assim, não apenas em categorias universais para a análise de qualquer realidade, mas também em proposições normativas que definem o dever ser para todos os povos do planeta. Estes conhecimentos convertem-se, assim, nos padrões a partir dos quais se podem analisar e detectar as carências, os atrasos, os freios e impactos perversos que se dão como produto do primitivo ou do tradicional em todas as outras sociedades (grifo meu).
\end{abstract}

Assim, categorias que fundamentam outras epistemologias são inferiorizadas e deixadas de lado em detrimento de uma única noção de escola.

Os projetos ME e NTFSI lutam igualmente contra a contradição presente na ação de apenas "escolarizar a cultura" como mencionado em atividades dos referidos projetos, as quais apontam para o risco de folclorizá-la, o que seria igualmente violento, destruindo espaços e dinâmicas de aprendizagem fundamentais à formação indígena. Para Sartorello, "é justamente dessa visão ideal típica que se questiona a ontologia da cultura escolar e se constrói um currículo baseado na pedagogia indígena" (2014, p. 12). 
Por isso, ambos os projetos buscam transcender a escola colonizadora, em direção a uma escola comunitária ou até mesmo autônoma e constituir amplo e distinto horizonte político, filosófico, epistêmico e pedagógico contra hegemônico. Algumas MEs da região de Chiapas/México, por exemplo, já constituem experiências de autonomia, rejeitando a institucionalização oficial escolar. Segundo a ME de Kakete/Chiapas que tem como base o plantio do milho,"as escolas oficiais tentam não praticar a cultura” (Taller Interestatal Milpas Educativas, 2018).

No mesmo sentido, segundo uma renomada e antiga liderança da região de Chiapas, trabalhar com as MEs é muito importante para o processo de formação de crianças indígenas chiapanecas. Para a mesma, se referindo as dinâmicas particulares das milpas educativas, esta "pedagogia é como remédio".

Ambos também enfrentam uma série de obstáculos e conflitos comuns que devem ser superados e que em muitos casos constituem entraves para o desenvolvimento das atividades. No caso brasileiro, as Secretarias de Educação (SEDUCs) são geridas substancialmente por não indígenas e sempre que um dos projetos pedagógicos apresentam inovações estruturais ao sistema de ensino brasileiro, como considerar atividades tradicionais e rituais como dia letivo ou estabelecer uma matriz curricular transdisciplinar, por exemplo, agem contra estas experienciais no sentido da conservação de dinâmicas convencionas da escola colonizadora brasileira.

Percebo que, na realidade mexicana, sindicatos, secretarias e mesmo escolas atuam igualmente como forças contra as inovações propostas. Ficam evidentes, inclusive, a violência e a complexidade destes conflitos.

A própria relação com a comunidade é muitas vezes tensa, apontando para o fato de que não se tratam de unidades homogêneas e de que há diversos interesses envolvidos. Ademais, evidencia-se a situação de que às vezes é difícil igualmente o entendimento, por parte da comunidade, sobre as novas e inovadoras propostas pedagógicas.

Os professorxs da Escola Indígena 19 de abril, da aldeia Manoel Alves Pequeno, do povo Krahô, por exemplo, sempre mencionam as dificuldades iniciais em fazerem a comunidade entender os avanços propostos na dinâmica dos temas contextuais, base da experiência do NTFSI. Segundo elxs, 
hoje, as dinâmicas das aulas são diferentes. Em uma semana trabalhamos com tema contextual e na outra semana com disciplinas. Nas disciplinas trabalha-se os conteúdos que vêm dos conhecimentos tirados dos livros, do cupẽ (não indígena). $\mathrm{O}$ tema contextual é bem diferente da disciplina. Ele tem a ver com teoria e com as novas práticas pedagógicas que buscam preservar, proteger e gerir o território dos mehĩs (indígenas). Assim, os alunos aprendem dois conhecimentos, o do cupẽ e o do mehĩ. Nos temas contextuais trabalhamos com os conteúdos voltados para nossa cultura e fazemos os alunos pesquisarem fora da escola, no pátio. Ou ainda com os anciãos, pessoas sábias que têm mais experiência, e têm mais conhecimento para transmitir. Desta forma, conhecimentos que são repassados de geração para geração agora vão à sala de aula. Além disso, com o tema contextual os alunos têm a liberdade de participar das festas culturais realizadas pela comunidade e também aprender a praticar a corrida de tora, corrida de flecha, trabalhar na roça, pescar ou então caçar junto com os caçadores da aldeia. Isto significa que a escola se preocupa com a valorização da nossa própria cultura (COMITÊ KRAHÔ, 2017, p.24-25).

No mesmo sentido, para uma professora de Puebla, em referência ao ME, a resposta da comunidade após conhecer o projeto é positiva. Para ela, antes "os papais pensavam que o tempo da escola estava perdido" (Taller Interestatal Milpas Educativas, 2018).

Conclui-se que a eficácia da transformação escolar e de mundo proposta e presente em ambos os projetos dependem de uma transformação epistemológica de fato, presente na mudança de paradigma e conceitos para se pensar a educação e o mundo. Um ancião chiapaneco afirmou que se deve usar "nossa própria terminologia" (Taller Interestatal Milpas Educativas, 2018). Segundo ele, "temos que construir uma pedagogia intercultural [...] o conhecimento indígena deve estar na aula" (Ibidem).

No âmbito do NTFSI, Herbetta e Pimentel (2017) afirmam que os TCs têm como centro "atuar com base em um pensamento-outro, evidenciado a partir de uma relação simétrica com os saberes indígenas e chamados aqui de nova base epistêmica" (p. 5).

A nova base epistêmica aponta para um pensamento apto a perceber as ligações, as interações, as implicações mútuas, mas, ao mesmo tempo, apto em perceber a diferenciação e a oposição entre os saberes. É o que Walsh chamaria de interculturalidade crítica. Segundo a autora, "o projeto de interculturalidade crítica é proposto como um pensamento outro que se afirma na América Latina como um projeto alternativo de natureza ética, ontológica, epistêmica e política" (2013, p. 74). Trata-se de um processo de co-teorização.

Para Rappaport, "ainda mais significativo é o espaço que abre o processo de coteorização com os grupos que estudamos, proporcionando aos nossos interlocutores e a nós mesmos, novas ferramentas conceituais para dar sentido às realidades contemporâneas" (2007, p. 201). Para a autora ainda trata-se da 
produção coletiva de veículos conceituais que remontam tanto a um corpo de teorias antropológicas quanto aos conceitos desenvolvidos por nossos interlocutores. Em essência, este empreendimento tem o potencial de criar formas de teoria que a academia contempla apenas parcialmente pelo seu conteúdo (p. 204).

Na mesma direção, o texto de Sartorello, um dos coordenadores do projeto Milpas Educativas afirma que o

\begin{abstract}
processo de co-teorização intercultural encontra o seu núcleo gerador (seu coração, dizem os maias) nos códigos vivos através dos quais meus colaboradores maias sintetizam os princípios da pedagogia indígena aprendida e praticada na vida e nas escolas da comunidade. Estes códigos constituem o ponto de partida para o diálogo com outras categorias - que temos chamado fusionadas - as quais expressam a união de horizontes dos diferentes sujeitos participantes (assessores kaxlanes e colaboradores indígenas), bem como com aquelas categorias teóricas produzidas por outros autores e que são as que permitem ampliar o alcance teórico da co-teorização intercultural (2014, p. 15).
\end{abstract}

Ambos os projetos buscam, portanto, produzir um conhecimento que, segundo Dietz, Guilherme e Sousa Santos (2016, p. 201), "promove os saberes ecológicos, plurais e contrahegemônicos".

Uma nova escola indígena deve ser contextualizada nas diferentes visões de mundo existentes, as quais devem ser a base para o desenho de políticas públicas para gerar bemestar para as respectivas populações.

\title{
Referências
}

BERTELY, Maria. Conociendo nuestras escuelas - un acercamiento etnografico a la cultura escolar. Maestros y ensenaza Paidos. Paidos, 2008.

CAXET, Roberto Krahô. Comunicação oral. Etapa de Estudos em Terra Indígena Krahô, 2013. Aldeia Manoel Alves Pequeno. Núcleo Takinahakỹ de Formação Superior Indígena. Universidade Federal de Goiás.

COMITÊ KRAHÔ/NTFSI. Pahte mẼ amjĩ ton xà itajê cunẼa, nẼ rỲ ipinkrên nare, kôt cu pahtyj $\mathrm{mE}$ to ihtỲj, mẼ pah cunẼa jakry xà caxuw : subsídios à prática pedagógica musical $\mathrm{e}$ decolonial a partir de experiências escolares Krahô / Taís Põcuhtô; Juliana TêrkwỲj; Leonardo TupẼ̃n (Org.). [et al.]. Goiânia: Editora da Imprensa Universitária, 2017.

CUSICANQUI, Silvia. Chixinakax Utxiwa (prácticas y Discursos Descolonizadores). Argentina: Tinta Limon, 2018. 
DIETZ Gunther; GUILHERME, Manuela; SOUSA SANTOS, Boaventura. Da universidade à pluriversidade: reflexões sobre o presente e o futuro do ensino superior. Revista Lusófona de Educação, 31, 201-212, 2015.

FREIRE, Paulo. Educação e mudança. Rio de Janeiro: Paz e Terra, 1982.

GASCHÉ, J. Niños, maestros, comuneros y escritos antropológicos como fuentes de contenidos indígenas escolares y la actividad como punto de partida de los procesos pedagógicos interculturales: Un modelo sintáctico de cultura", en Bertely, M.; Gasché, J. y Podestá, R. (coords.)Educando en la diversidad. Investigaciones y experiencias educativas interculturales y bilingües, pp. 279-365, Quito, Ecuador: Abya-Yala, 2008.

GRUPIONI, L. D. B. Contextualizando o campo da formação de professores indígenas no Brasil. Em: GRUPIONI, L. D. B. (Org). Formação de professores indígenas: repensando trajetórias. Brasília: MEC, 2006.

HERBETTA, Alexandre; PIMENTEL, Maria do Socorro. Educação indígena e interculturalidade: um debate epistemológico e politico/Educacion indigena e interculturalidad: un debate epistemologico y politico/ Mariano Baez Landa; Alexandre Ferraz HERBETTA (Org.). - bilíngue - Goiânia: Editora da Imprensa Universitária, 2017.

LUCIANO BANIWA, Gersem. Educação para o manejo de mundo. Entre a escola ideal e a escola real no Alto Rio Negro. Rio de Janeiro: LACED/Contra-Capa, 2014.

KAMER, Julio. Xahta mẽ pahte amnhĩ nhĩpex ho hihtỳx (sustentabilidade): a relação entre queimadas e cantorias no território Apinaje. Projeto Extraescolar. NTFSI/UFG, 2012.

LANDER, Edgardo. Colonialidade do saber: eurocentrismo e ciências sociais (perspectivas latino-americanas). Buenos Aires: CLACSO, 2005, p.55-70.

MUNDURUKU, Daniel. A escrita e a autoria fortalecendo a identidade. Disponível em: <https://pib.socioambiental.org/pt/A_escrita_e_a_autoria_fortalecendo_a_identidade>.

Acessado em: 12 nov. 2018.

PIIKEN, Dodanin. Comunicação oral. Etapa de Estudos em Terra Indígena Krahô, 2013. Aldeia Manoel Alves Pequeno. Núcleo Takinahakỹ de Formação Superior Indígena. Universidade Federal de Goiás.

PIMENTEL, Maria do Socorro et al. Projeto Político Pedagógico. Núcleo Takinahakỹ de Formação Superior Indígena. Universidade Federal de Goiás, 2006.

PIMENTEL DA SILVA, Maria do Socorro. A pedagogia da esperança na construção de práticas pedagógicas contextualizadas e emancipatórias. Em: PIMENTEL DA SILVA, Maria do Socorro; BORGES, Mônica Veloso (Orgs.), 2013.

RAPPAPORT, J. "Más allá de la escritura. La epistemología de la etnografía em colaboración". Revista Colombiana de Antropología, 43, pp. 197-229, 2007. 
SARTORELLO, Stefano Claudio. La co-teorización intercultural de un modelo curricular en Chiapas, México. Revista Mexicana de Investigación Educativa. RMIE, 2014, vol. 19, n. 60, p. 73-101 (ISSN: 14056666).

SARTORELlO, Stefano; BERTELY, Maria. Projeto Milpas Educativas: Laboratorios socionaturales vivos para el Buen Vivir. Universidad Ibero Americana. México, 2016.

Taller Interestatal Milpas Educativas" realizada de 20 a 23 de setembro de 2018 na Casa Xitla, CDMX.

III Seminário do Curso de Especialização em Educação Intercultural e Transdisciplinar: gestão pedagógica. Núcleo Takinahakỹ de Formação Superior Indígena. Universidade Federal de Goiás. 30 de junho a 4 de julho de 2014.

WALSH, Catherine. Pedagogia decoloniales. Practicas insurgentes de resistir, (re) existir y (re) vivir. Tomo I. Serie Pensamiento Decolonial. Abya Yala, 2013.

Submetido em 28 de junho de 2019.

Aceito em 08 de agosto de 2019.

Publicado em 09 de agosto de 2019. 